\title{
Epinephelus tankahkeei, a new species of grouper (Teleostei, Perciformes, Epinephelidae) from the South China Sea
}

\author{
Haohao Wu', Meng Qu', Hungdu Lin², Wei Tang', Shaoxiong Ding ${ }^{1,3}$ \\ I Marine Biodiversity and Global Change Research Center, College of Ocean and Earth Science, Xiamen Uni- \\ versity, Xiamen 361102, China 2 The Affliated School of National Tainan First Senior High School, Tainan, \\ Taiwan 3 Function Laboratory for Marine Fisheries Science and Food Production Processes, Qingdao National \\ Laboratory for Marine Science and Technology, Qingdao 266200, China
}

Corresponding author: Shaoxiong Ding (sxding@xmu.edu.cn)

Academic editor: M. E. Bichuette | Received 15 September 2019 | Accepted 23 March 2020 | Published 18 May 2020

http://zoobank.org/B1A5BC73-85F1-4583-9F46-93B844736F36

Citation: Wu H, Qu M, Lin H, Tang W, Ding S (2020) Epinephelus tankahkeei, a new species of grouper (Teleostei, Perciformes, Epinephelidae) from the South China Sea. ZooKeys 933: 125-137. https://doi.org/10.3897/ zookeys.933.46406

\begin{abstract}
A new species of grouper, Epinephelus tankahkeei sp. nov. is described from the South China Sea based on examination of morphological and molecular characteristics. This new species has been treated as, and is similar to, its congener E. chlorostigma. Epinephelus tankahkeei sp. nov. can be distinguished from $E$. chlorostigma by the following combination of characters: a convex anal fin; closer dark spots on the body; a lack of dark spots on the abdomen, cheek, and pectoral fin; the absence of a clear posterior white margin on the caudal fin. Molecular analyses of the mitochondrial COI sequence variation, genetic distances, and a phylogeny, all highly support E. tankahkeei sp. nov. as a distinct species. A key to E. tankahkeei sp. nov. and its most closely related species is provided.
\end{abstract}

\section{Keywords}

Epinephelidae, Epinephelus tankahkeei, groupers, new species, South China Sea

\section{Introduction}

The groupers are an assemblage of reef fishes in the perciform family Epinephelidae (Smith and Craig 2007; Craig et al. 2011; Zhuang et al. 2013), comprising more than

Copyright Haohao Wu et al. This is an open access article distributed under the terms of the Creative Commons Attribution License (CC BY 4.0), which permits unrestricted use, distribution, and reproduction in any medium, provided the original author and source are credited. 
160 species in 16 genera (Heemstra and Randall 1993; Craig et al. 2011). The genus Epinephelus Bloch, 1793 (type species: Epinephelus marginalis Bloch, $1793=$ Epinephelus fasciatus) is the most biologically diverse of all grouper genera (Heemstra and Randall 1993) and contains more than 90 valid species (Frable et al. 2018). These species are characterized by an elongate, robust (subcylindrical), oblong or deep and compressed body; a dorsal fin usually with XI spines (X spines in some species) and 12 to 19 rays; and an anal fin with III distinct spines and 7 to 10 (very rarely 7 or 10) rays. Epinephelus spp. are widespread in the rocky and reef shores of tropical and subtropical oceans, and are usually apex predators in their habitats. They are also commercially important and constitute a significant component of coastal fisheries (Dalzell et al. 1996). Due to the ecological and economic importance of these species, their alpha taxonomy and phylogenetic relationships have been well reviewed (Craig and Hastings 2007; Ma et al. 2016). However, groupers appear to have undergone rapid sympatric speciation and usually show fewer differences in morphology between closely related species, thus some cryptic species might still be undiscovered. Therefore, the use of genetic data is of considerable importance in grouper taxonomic and diversity research (Gilles et al. 2000; Han et al. 2011).

In recent years, we collected a new form of grouper from the South China Sea that had been previously regarded as Epinephelus chlorostigma. Further investigation based on morphometric and molecular characteristics shows that this new form should be a new species of the genus Epinephelus. Herein, we describe this new species as Epinephelus tankahkeei. In addition, a key to E. tankahkeei sp. nov. and its most closely related species is provided.

\section{Materials and methods}

Between 2011 and 2019, nine specimens of the new species were collected from fish markets and fishing boats in Xiamen, Shenzhen, Sansha, and Haikou, China. ODV v5.1.5 software was used to generate a collection site map (Schlitzer 2002). The sampling localities are listed in Suppl. material 1: Table S1. The holotype and paratypes were fixed and preserved in anhydrous ethanol. The specimens were stored in the Fish Collection of the College of Ocean and Earth Sciences, Xiamen University. Institutional codes followed Sabaj (2016).

The methods of counting and measurement followed Randall and Heemstra (1993) and include: total length; standard length (as SL); head length; snout length; body depth; body width; orbit diameter; interorbital width; preorbital depth; maxilla width; upper jaw length; lower jaw length; length of pelvic-fin and anal-fin spines; lengths of the dorsal, anal, pectoral, pelvic and caudal fins; caudal-peduncle depth; caudal-peduncle length; predorsal length; preanal length; prepelvic length; dorsal-fin base; longest hard dorsal spine; longest soft dorsal ray; anal-fin base; and length of the third anal spine, longest anal soft ray, and pelvic-fin spine. The following counts were made: gill rakers, lateral-line scales, lateral scale series, pectoral-fin rays, anal-fin rays, dorsal-fin rays, pelvic-fin rays, caudal-fin rays, and vertebras. 
The procedures for DNA isolation, PCR amplification and sequencing followed $\mathrm{Qu}$ et al. (2018). DNA was extracted using the standard phenol-chloroform protocol and the ethanol precipitation method and then stored at $-20{ }^{\circ} \mathrm{C}$. Polymerase chain reaction (PCR) was performed to amplify the partial fragment of the mitochondrial COI locus using a pair of primers (Fish F1, 5'-TCAACCAACCACAAAGACATTGGCAC-3' and Fish R1, 5'-TAGACTTCTGGGTGGCCAAAGAATCA-3') (Ward et al. 2005). The thermal cycler program for PCR was $95^{\circ} \mathrm{C}$ for $5 \mathrm{~min}$, followed by 35 cycles of $94{ }^{\circ} \mathrm{C}$ for $30 \mathrm{~s}, 52{ }^{\circ} \mathrm{C}$ for $30 \mathrm{~s}$ and $72{ }^{\circ} \mathrm{C}$ for $45 \mathrm{~s}$ and a final extension at $72^{\circ} \mathrm{C}$ for $10 \mathrm{~min}$. The products were checked by electrophoresis on a $1 \%$ agarose gel to confirm the predicted fragment size and were then sequenced. The sequencing results were trimmed and manually proofread using SEQUENCHER 5.4.6 (http://www. genecodes.com) software. All sequences in this study were deposited in GenBank, and the accession numbers are shown in Suppl. material 1: Table S1.

Due to the availability of data for other related species in GenBank, we chose the mitochondrial COI gene sequence to calculate intraspecific and interspecific genetic distances and perform maximum likelihood (ML) and Bayesian analyses in this study. The intraspecific and interspecific genetic distances were generated using the Kimura two-parameter (K2P) distance model with MEGA 7 (Kumar et al. 2016). For the phylogenetic analyses, Epinephelus akaara (GenBank No. MF185437) and Epinephelus awoara (GenBank No. MF185456) were used as the outgroups because they are located in a clade sister to the one containing the E. chlorostigma species-complex (Ma et al. 2016). jModelTest 2.1.9 was used to infer the best evolutionary model, and the $\operatorname{TrN}+\mathrm{I}+\mathrm{G}$ model was selected based on both the Akaike information criterion (AIC) and the Bayesian information criterion (BIC) (Darriba et al. 2012). ML phylogenetic analysis was performed with the PhyML 3.1 program with 1000 bootstrap replicates (Guindon and Gascuel 2003), and the Bayesian phylogenetic analysis was performed by using MrBayes 3.2.6 (Ronquist et al. 2012).

\section{Taxonomy}

\section{Epinephelus tankabkeei sp. nov.}

http://zoobank.org/1C62B8C1-33B3-4A75-88D9-C49B5897EA55

Figs 1, 2; Table 1

Type material. Holotype: ZMUA-eptan06, $244.5 \mathrm{~mm}$ SL, Caught in Yongxing Island, Sansha, Hainan, 2 April 2017. Paratypes: ZMUA-eptan01, 111.0 mm SL, China, purchased at a fish market in Xiamen, Fujian, China, 1 September 2011, reported as collected in the south Taiwan Strait; ZMUA-eptan02, $233.2 \mathrm{~mm} \mathrm{SL}$, purchased at the Bashi market in Xiamen, Fujian, China, 22 August 2016, reported as collected in the south Taiwan Strait; ZMUA-eptan03, $215.4 \mathrm{~mm}$ SL, collected with the ZMUAeptan02; ZMUA-eptan04, $262.5 \mathrm{~mm} \mathrm{SL}$, purchased at a fish market in Shenzhen, Guangdong, China, 15 February 2017, reported as collected in the South China Sea; ZMUA-eptan05, $232.6 \mathrm{~mm} \mathrm{SL}$, collected with the holotype; ZMUA-eptan07, 


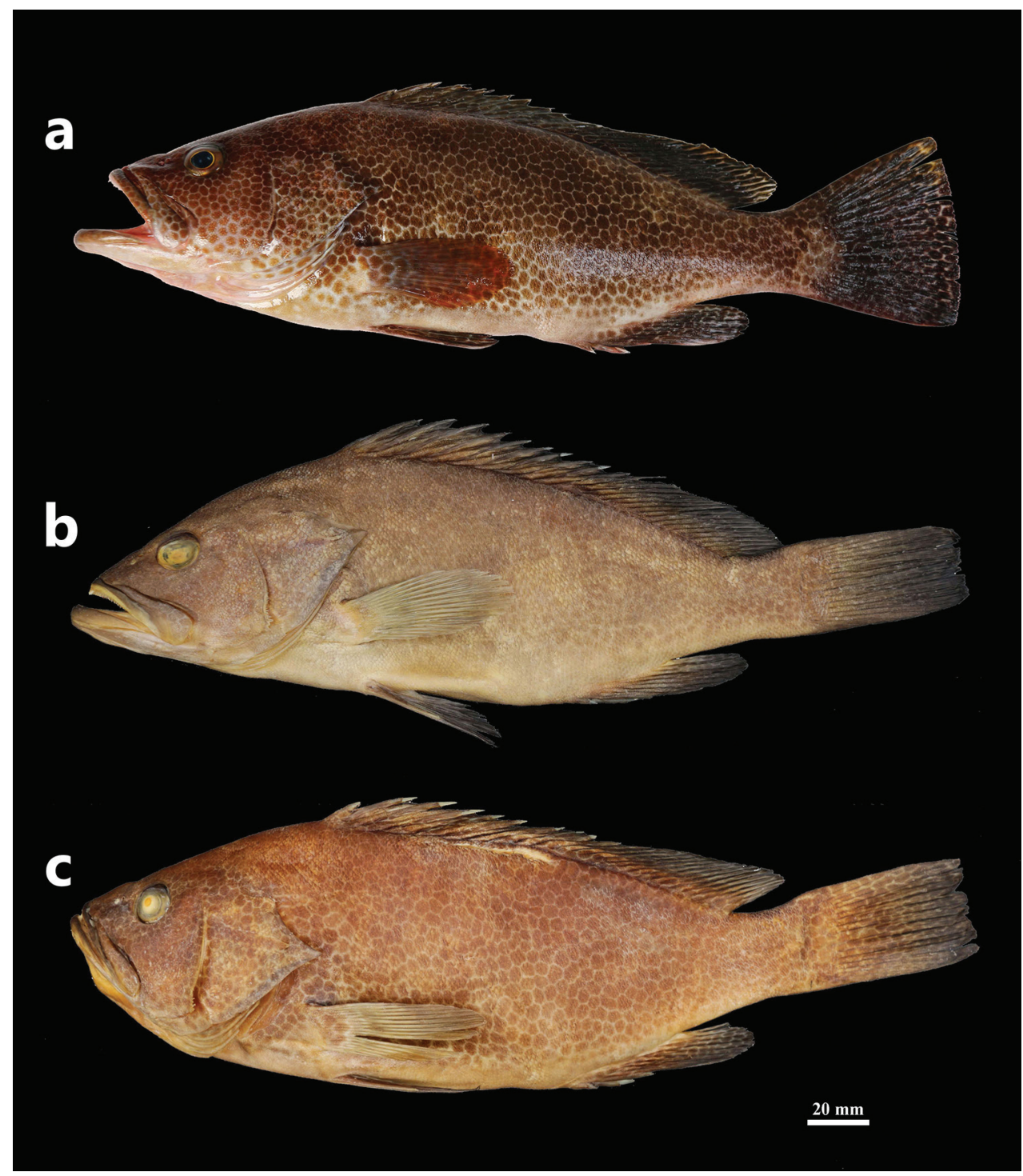

Figure I. Epinephelus tankahkeei a holotype, ZMUA-eptan06, $244.5 \mathrm{~mm}$ SL, Xisha Islands from the South China Sea b preserved holotype c paratype, ZMUA-eptan02, $233.2 \mathrm{~mm} \mathrm{SL}$, purchased at the Bashi market in Xiamen, Fujian, China, 22 August 2016.

$252.9 \mathrm{~mm}$ SL, purchased at a fish market in Shenzhen, Guangdong, China, 1 July 2017, reported as collected in the South China Sea; ZMUA-eptan08, $274.2 \mathrm{~mm}$ SL, China, purchased at a fish market in Xiamen, Fujian, China, 31 July 2018, reported as collected in the south Taiwan Strait. ZMUA-eptan09, $186.5 \mathrm{~mm} \mathrm{SL}$, China, purchased at a fish market in Haikou, Hainan, China, 22 March 2019, reported as captured using a trawl net in Mulan Bay, Wenchang, Hainan. 


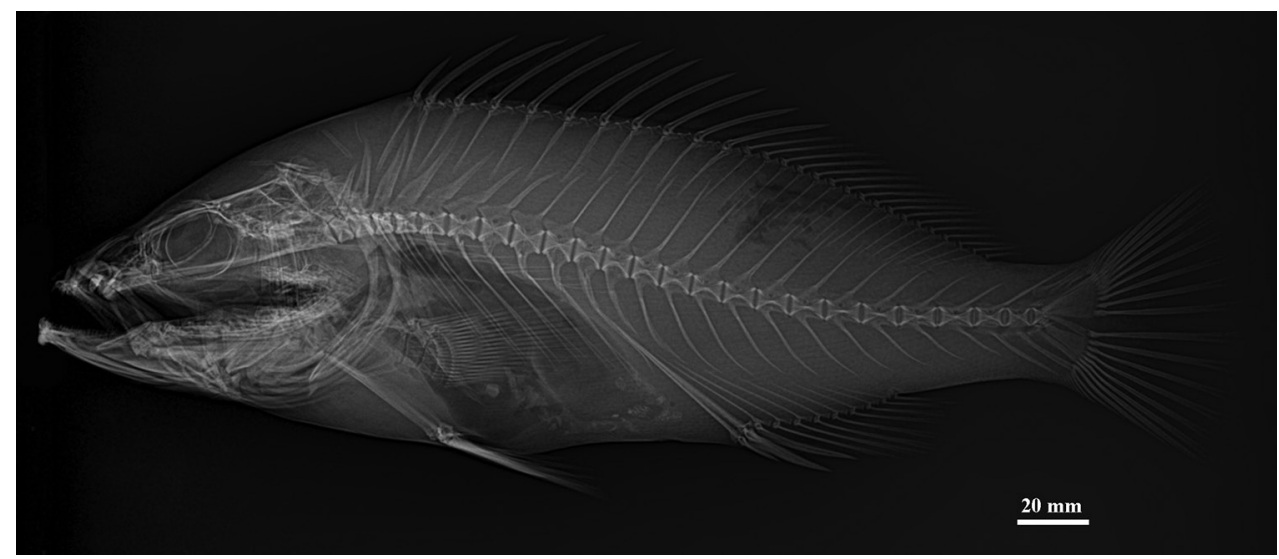

Figure 2. Epinephelus tankahkeei sp. nov. Radiograph of paratype ZMUA-eptan08, $274.2 \mathrm{~mm}$ SL.

Diagnosis. Epinephelus tankahkeei sp. nov. can be distinguished from all other Indo-Pacific Epinephelus species by the following characteristics: dorsal-fin rays XI, 16-18 (vs. 14-15 in Epinephelus gabriellae); anal-fin rays III, 8; pectoral-fin rays 16 or 17; lateral-line scales 47-51 (vs. 65-72 in Epinephelus polylepis); caudal fin convex (vs. slightly emarginate or truncate caudal fin in E. chlorostigma, Epinephelus areolatus, Epinephelus bleekeri, and Epinephelus geoffroyi); anal fin rounded (vs. angular anal fin in E. chlorostigma, and E. geoffroyi); membranes of spinous portion of dorsal fin slightly incised; head (except chest), body (except abdomen), and fins (pectoral fin spotted only basally) with numerous, irregular, close-set, dark brown spots, becoming more widely spaced on the lower part, the ground color forming a pale network (vs. lager spots in Epinephelus miliaris, and E. areolatus); rear margin of the caudal fin without a narrow white line (vs. a clear white margin posteriorly on the caudal fin in E. chlorostigma, and E. areolatus).

Description. Dorsal-fin rays XI, 16 (16-18); anal-fin rays III, 8; pectoral-fin rays 16 (16 or 17); lateral-line scales 51 (47-51); lateral scale series 123 (111-123); gill rakers $10(10-11)+15(14-16)$; vertebra 24; body slightly elongated and body depth less than head length. Body depth contained 3.2 (3.0-3.2) in standard length. Body laterally compressed and body width 2.6 (2.1-2.6) in body depth. Head length 2.7 (2.5-2.7) in SL; orbit diameter 6.1 (4.9-6.8) in head; snout length 3.8 (3.6-4.0) in head. Dorsal profile of head nearly straight except at the snout with a slight notch before eyes. Interorbital region convex, width $6.3(5.6-7.2)$ in head; preorbital depth 7.8 (7.8-11.3) in head; caudal-peduncle length 1.9 (1.8-2.2) in head; caudal-peduncle depth $3.3(3.2-3.7)$.

Mouth large and lower jaw slightly projecting and oblique. Lower jaw 3.4 (3.43.9) in head length; upper jaw $2.4(2.3-2.5)$ in head. Maxilla slightly extending to rear edge of eye and posterior edge of maxilla slightly rounded. Maxilla width 8.1 (7.9-9.2) in head. One or two pairs of canine teeth at anterior part of the upper and lower jaw. Teeth of lower jaw form two rows and expand anteriorly into three rows; teeth in the 
Table I. Meristics and measurements for type specimens of Epinephelus tankabkeei and E. chlorostigma. The dashes indicate that data were not collected due to specimen damage, which prevented an accurate measurement or count.

\begin{tabular}{|c|c|c|c|c|}
\hline & \multicolumn{2}{|c|}{ Epinephelus tankabkeei } & \multicolumn{2}{|c|}{ E. chlorostigma } \\
\hline & ZMUA-eptan06 (holotype) & Range for all type specimens & ANSP 103722 & ANSP 163245 \\
\hline Standard length $(\mathrm{mm})$ & 244.5 & $111-274.2$ & 281 & 398 \\
\hline Total length (mm) & 286.2 & $136.5-334.7$ & 355 & 503 \\
\hline Dorsal-fin ray count & $\mathrm{XI}, 17$ & XI, 16-18 & $\mathrm{XI}, 16$ & XI, 16 \\
\hline Anal-fin ray count & III, 8 & III, 8 & III, 8 & III, 8 \\
\hline Pectoral-fin ray count & 16 & $16-17$ & 18 & 17 \\
\hline Pelvic-fin ray count & $\mathrm{I}+5$ & $\mathrm{I}+5$ & $\mathrm{I}+5$ & $\mathrm{I}+5$ \\
\hline Lateral line scales & 51 & $47-51$ & 52 & 58 \\
\hline Lateral scale series & 123 & $111-123$ & 102 & 106 \\
\hline Gill rakers count & $10+15$ & $10-11+14-16$ & $9+14$ & $8+18$ \\
\hline \multicolumn{5}{|l|}{$\%$ of SL } \\
\hline Body depth & 31.1 & $31.1-33.7$ & 34.9 & 35.6 \\
\hline Body width & 12.2 & $12.2-15.6$ & 16.3 & 18.1 \\
\hline Head length & 37.1 & $36.9-39.6$ & 38.7 & 39.2 \\
\hline Snout length & 9.8 & $9.5-10.9$ & 10.0 & 10.1 \\
\hline Orbit diameter & 6.1 & $5.7-8$ & 7.5 & 6.1 \\
\hline Preorbital depth & 4.8 & $3.5-4.8$ & 4.7 & 4.5 \\
\hline Interorbital width & 5.8 & $5.5-6.7$ & 7.2 & 8 \\
\hline Maxilla width & 4.6 & $4.1-4.8$ & 4.9 & 5.1 \\
\hline Upper jaw length & 15.6 & $15.6-17.1$ & 18.0 & 17.5 \\
\hline Lower jaw length & 11 & $8.6-11.5$ & 12.4 & 11.7 \\
\hline Caudal peduncle depth & 11.1 & $10.5-12.1$ & 11.9 & 10.8 \\
\hline Caudal peduncle length & 19.2 & $18-21.1$ & 20.0 & 22.7 \\
\hline Predorsal length & 34.6 & $32.4-38.8$ & 36.4 & 36.5 \\
\hline Preanal length & 63.4 & $58.5-69.1$ & 68.7 & 73.9 \\
\hline Prepelvic length & 36.8 & $34.8-40.8$ & 38.8 & 34.7 \\
\hline Dorsal-fin base & 53.4 & $53.1-61.4$ & 59.4 & 54.8 \\
\hline Longest hard dorsal ray & 14.3 & $12.4-14.4$ & 15.7 & 14.3 \\
\hline Longest soft dorsal ray & 15.2 & $13.4-16.9$ & 14.5 & 15.4 \\
\hline Anal-fin base & 15 & $14.8-17.3$ & 15.4 & 16.2 \\
\hline Third anal spine length & 10.7 & $9.3-13.3$ & 10.0 & 8.1 \\
\hline Longest anal soft ray & 17.3 & $14.9-21.1$ & 15.7 & 15 \\
\hline Caudal-fin length & 22.1 & $18.7-24.2$ & 25.5 & 22.3 \\
\hline Pectoral-fin length & 20.1 & $19.6-23.2$ & 20.9 & 20.2 \\
\hline Pelvic-fin length & 19.5 & $18.1-21.7$ & 20.4 & 17.4 \\
\hline Pelvic spine length & 11 & $9.7-12.6$ & 10.4 & 9.2 \\
\hline
\end{tabular}

outer side are larger than the inner side. Villiform teeth present on vomer and palatines. Tongue slender and sharp at tip. Longest gill raker was greater in length than longest gill filament. Nostrils round and posterior nostril larger than anterior nostril. Anterior nostril with a membranous flap.

Three spines on operculum, topmost and undermost small, the middle the largest. Tip of middle spine extending farther towards tail than tip of lower spine. Upper edge of opercular membrane slightly convex coming to a rounded point posteriorly. Preopercle rounded with four to five prominent spines at angle and with numerous fine serrae while increasing in size downward. Lateral line starting from posterior opercle and slightly arched over pectoral region. Scales on head, thorax, abdomen, anterodorsal part of body and fin membranes weakly ctenoid. Auxiliary scales absent. Small 
scales present on inner margins of dorsal, pectoral, pelvic, and caudal fins and not extending to the rear margin area.

Origin of dorsal fin before pectoral-fin base. Membranes of spinous portion of dorsal fin slightly incised. First dorsal spine contained 1.9 (1.6-2.0) times in second spine; second spine $1.2(1.2-1.5)$ times in longest spine (third and fourth spine); longest spine contained $2.6(2.6-3.1)$ in head length. Longest soft dorsal ray $2.4(2.3-2.8)$ in head. Anal-fin origin below origin of first soft dorsal ray. First anal spine 2.0 (1.9-2.3) times in second anal spine; second anal spine $1.2(1.1-1.4)$ times in third anal spine; third anal spine longest 3.5 (3.0-4.1) in head. Longest anal-fin rays 2.1 (1.9-2.5) in head. Caudal fin convex, $1.7(1.6-2.0)$ in head. Middle pectoral rays longest, 1.8 $(1.7-1.9)$ in head and reaching to base of $9^{\text {th }}$ dorsal spine. Origin of pelvic fin slightly posterior to pectoral-fin base.

Coloration in life (based on photographs of the fresh holotype and paratypes). Head (except chest), body (except abdomen), and fins (pectoral fin only basally) with numerous, irregular, close-set, dark brown spots becoming more widely spaced on the lower part and with the ground color forming a pale network (Fig. 1a); dorsal fin, caudal fin and anal fin dark brown; pectoral fin translucent with reddish brown to light yellowish-brown; body sometimes with four faint, irregular, discrete dark bars; rear margin of the caudal fin without a narrow white line.

Coloration in preservative. Body yellowish-brown to tan with close-set spots remaining prominent or faded (Fig. 1b, c). Dorsal, caudal, and anal fins dark brown. Pectoral fin pale and opaque.

Genetic analyses. Mitochondrial COI gene sequences were obtained from nine specimens of E. tankahkeei. Several sequences of related species were also sequenced in this study or obtained from GenBank. E. tankahkeei has 13 speciesspecific mutations at nucleotide positions 126, 216, 222, 249, 276, 372, 414, $519,525,528,558,567$, and 576 (Table 2). The intraspecific mean distance of $E$. tankahkeei was 0.0028 . The interspecific mean distances indicated that E. tankahkeei differs from E. chlorostigma by 0.0621 , from $E$. polylepis by 0.0771 , from $E$. gabriellae by 0.1263 , from E. miliaris by 0.0904 , from $E$. geoffroyi by 0.1219 , and from E. areolatus by 0.0855 (Table 3 ). Phylogenetic trees using both maximum likelihood and Bayesian inference showed almost complete agreement, with $E$. tankahkeei forming a monophyletic clade that excluded all other closely related species (Fig. 3).

Distribution and habitat. The new species was recently observed in the South China Sea and Taiwan Strait. Similar to other congeners, E. tankahkeei is a reef-associated species that feeds on fishes and invertebrates.

Table 2. Species-specific mutation sites in the COI gene for Epinephelus tankahkeei.

\begin{tabular}{lccccccccccccc}
\hline & \multicolumn{10}{c}{ Nucleotide position (beginning from 5' end) } \\
\cline { 2 - 12 } & $\mathbf{1 2 6}$ & $\mathbf{2 1 6}$ & $\mathbf{2 2 2}$ & $\mathbf{2 4 9}$ & $\mathbf{2 7 6}$ & $\mathbf{3 7 2}$ & $\mathbf{4 1 4}$ & $\mathbf{5 1 9}$ & $\mathbf{5 2 5}$ & $\mathbf{5 2 8}$ & $\mathbf{5 5 8}$ & $\mathbf{5 6 7}$ & $\mathbf{5 7 6}$ \\
\hline Epinephelus tankahkeei & T & C & C & A & C & G & G & T & G & C & T & G & C \\
Other closely related species in this study & C & A, G & T & T, C & A & A & A & A, G & C & G, A & A, G, C & A & A, T \\
\hline
\end{tabular}


Table 3. Analysis of the intraspecific and interspecific (K2P model) distances, interspecific distances (in lower left) and standard errors (in upper right) based on the COI locus between Epinephelus tankahkeei and closely related species; IMD = Intraspecific mean distance; $\mathrm{SE}=$ standard error.

\begin{tabular}{|c|c|c|c|c|c|c|c|c|c|c|c|}
\hline \multirow[b]{2}{*}{ Group } & \multirow[b]{2}{*}{ Species } & \multirow[b]{2}{*}{$N$} & \multirow[b]{2}{*}{ IMD } & \multirow[b]{2}{*}{ SE } & \multicolumn{7}{|c|}{ Interspecific Mean Distance } \\
\hline & & & & & 1 & 2 & 3 & 4 & 5 & 6 & 7 \\
\hline 1 & Epinephelus tankabkeei & 9 & 0.0028 & 0.0010 & - & 0.0112 & 0.0100 & 0.0144 & 0.0123 & 0.0141 & 0.0122 \\
\hline 2 & E. polylepis & 4 & 0.0031 & 0.0015 & 0.0771 & - & 0.0093 & 0.0144 & 0.0127 & 0.0136 & 0.0119 \\
\hline 3 & E. chlorostigma & 6 & 0.0030 & 0.0013 & 0.0621 & 0.0545 & - & 0.0143 & 0.0110 & 0.0138 & 0.0110 \\
\hline 4 & E. gabriellae & 2 & 0.0016 & 0.0015 & 0.1263 & 0.1142 & 0.1169 & - & 0.0148 & 0.0066 & 0.0154 \\
\hline 5 & E. miliaris & 2 & 0.0000 & 0.0000 & 0.0904 & 0.0885 & 0.0730 & 0.1143 & - & 0.0143 & 0.0122 \\
\hline 6 & E. geoffroyi & 2 & 0.0047 & 0.0026 & 0.1219 & 0.1073 & 0.1107 & 0.0321 & 0.1107 & - & 0.0143 \\
\hline 7 & E. areolatus & 3 & 0.0031 & 0.0018 & 0.0855 & 0.0831 & 0.0641 & 0.1239 & 0.0918 & 0.1152 & - \\
\hline
\end{tabular}

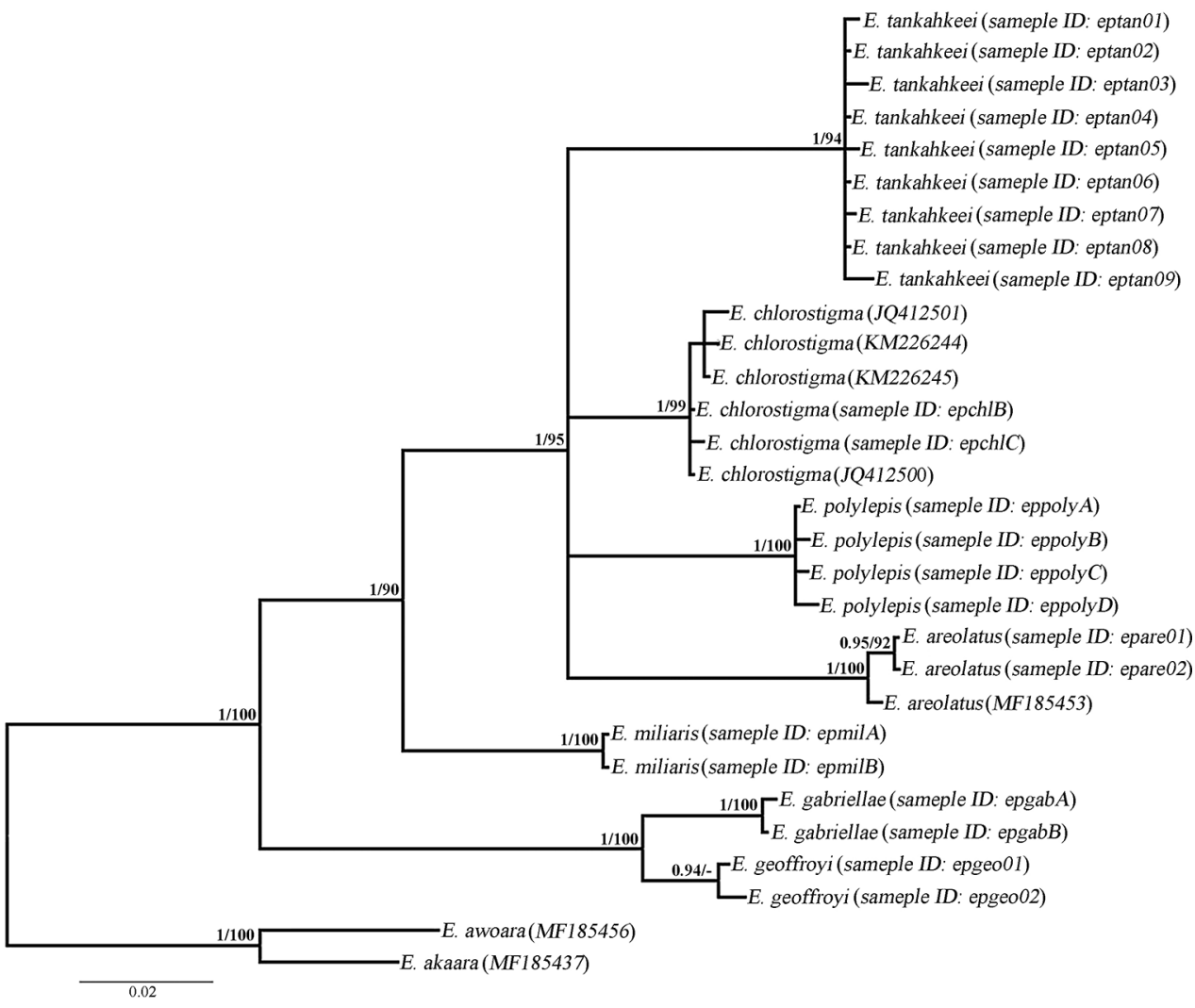

Figure 3. Bayesian phylogenetic tree of Epinephelus tankahkeei and closely related fish species. Numbers above nodes are Bayesian posterior probability values (left) and ML bootstrap values above 50 (right).

Etymology. Epinephelus tankahkeei is named after Tan Kah Kee (1874-1961), who was a famous overseas Chinese educator, philanthropist, and social activist and the founder of Xiamen University and Jimei School, in honor of his significant contribution to the motherland. 


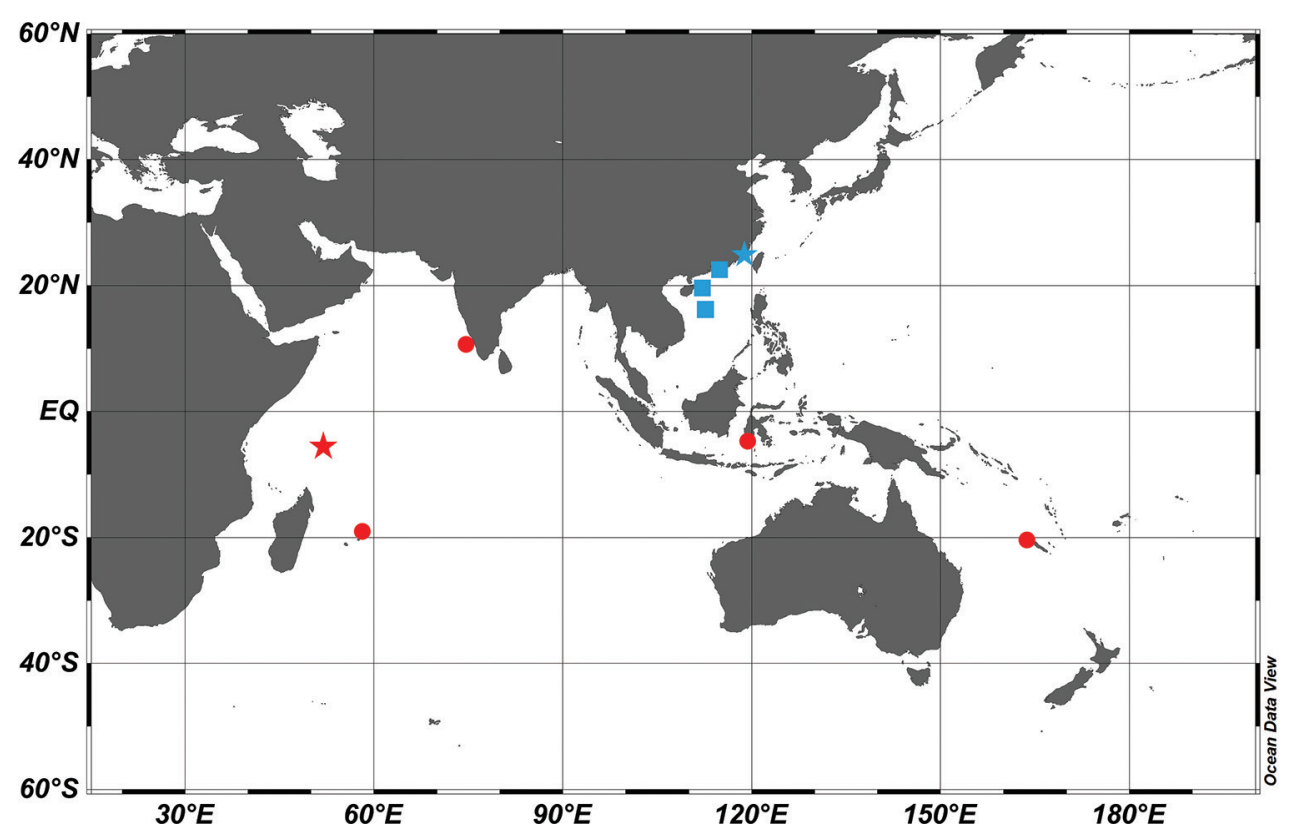

Figure 4. A map of the collection sites of Epinephelus tankahkeei (blue squares) and E. chlorostigma (red circles) examined in this study. The blue star represents the collection site of the E. tankahkeei holotype (ZMUA-eptan06), and the red star represents the type locality of E. chlorostigma.

\section{Discussion}

Epinephelus chlorostigma was formerly reported to have a wide distribution range from the Red Sea and the coast of Africa to the western Pacific Ocean. It was considered a species complex (the E. chlorostigma species complex) (Heemstra and Randall 1993). Since the early 1990s, new species have been successively distinguished from E. chlorostigma and described. Epinephelus gabriellae has a restricted range from Oman to Somalia and differs in having fewer dorsal-fin rays (14-15 vs. 16-18). Epinephelus polylepis is distributed from the western coast of India to the coast of Yemen and has more lateral-line scales and lateral-scale series (65-72 and 126-137 vs. 48-53 and 96-122, respectively) (Randall and Heemstra 1991). Epinephelus geoffroyi is local to the Red Sea and has more gill rakers (25-29 vs. 23-26) (Randall et al. 2013). Interestingly, the three recently described species above are all distributed to the west of the Indo-Australian Archipelago (IAA), even though the type locality of E. chlorostigma is the Seychelle Islands in the Indian Ocean. Currently, E. tankahkeei collected from the China Seas can be morphologically distinguished from E. chlorostigma by its rounder anal fin, closer dark spots on the body, lack of dark spots on the abdomen, and lack of a narrow, pale whitish posterior margin on the caudal fin.

Our molecular analyses also corroborated the morphological results. In E. tankahkeei, 13 species-specific mutations were found in the COI gene fragment (Table 2). Genetic distance analysis also revealed high divergence between $E$. tankahkeei and its closely 
related species. The interspecific mean distance between $E$. tankahkeei and E. chlorostigma was 0.0621 , which was greater than the distance $(0.0545)$ between $E$. chlorostigma and E. polylepis (Table 3). The phylogenetic analyses performed with both ML and Bayesian inference also revealed a distinct monophyletic group formed by all samples of $E$. tankahkeei, and this group was separated from E. chlorostigma, E. polylepis, and E. areolatus. Although the phylogenetic relationships of the four species could not be well resolved by only the COI gene, each of the species formed a monophyletic clade with high support, supporting their validity (the ML bootstrap value was $94 \%$ for $E$. tankahkeei, $99 \%$ for $E$. chlorostigma, $100 \%$ for E. polylepis, and 100\% for E. areolatus) (Fig. 3).

In the China Seas, the first record of E. chlorostigma was Serranus reevesii Richardson, 1846, type locality Canton, China (based on a painting by John Reeves) (Richardson 1846), which was later treated as a synonym of E. chlorostigma (Heemstra and Randall 1993). However, it is difficult to confirm the validity of $S$. reevesii due to its unclear description and lack of reliable photos and type specimen. As mentioned by Randall and Heemstra (1991), there are no confirmed records of E. chlorostigma in the continental waters of Asia. Our sampling in the China Seas over the last 20 years also never resulted in any $E$. chlorostigma specimens. Together with the distribution range, morphological characteristics, and molecular data, we suppose that most, or even all, of the former records of E. chlorostigma in the China Seas might be misidentifications of $E$. tankahkeei. More samples should be taken in the future to verify the distribution range of E. chlorostigma.

\section{Key to Epinephelus tankahkeei and closely related species}

1a Lateral-line scales 65-72, lateral-scale series 126-137 ................E. polylepis

1b Lateral-line scales 47-54, lateral-scale series 92-126 ...............................2

2a Dorsal-fin rays 14 or 15 ; body depth 3.2 to 3.6 times in standard length [coast of Oman, eastern border of Yemen, Somalia] ...................E. gabriellae

2b Dorsal-fin rays 16 to 18 (rarely 15 in E. areolatus); body depth 2.8 to 3.3

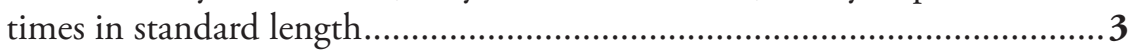

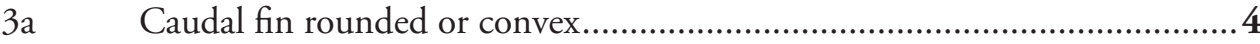

$3 \mathrm{~b}$ Caudal fin slightly emarginate (truncate on some specimens of $E$. chlorostigma)..... 5

$4 a \quad$ Body and fins with dark brown to black spots, those spots on fins (except spinous dorsal fin) much larger than those on body; lateral-scale series 92 to 108 [Indo-Pacific but not in Red Sea and Persian Gulf].

E. miliaris

$4 \mathrm{~b} \quad$ Body and fins with dark brown spots, becoming more widely spaced on the lower part; lateral-scale series 114 to 123 [South China Sea and Taiwan Strait]

E. tankabkeei

5a Dorsal-fin rays 15 to 17; anal fin margin in adults rounded or slightly angular; dark spots on body of adults subequal to pupil [Red Sea to western Pacific]

E. areolatus

5b Dorsal-fin rays 16 to 18 ; anal fin of adults angular; largest dark spots on body of adults distinctly smaller than pupil 
6a Posterior margin of caudal fin without a narrow, clear whitish margin; margin of anal fin distinctly angular; gill rakers 25-29 [Red Sea] .......... E. geoffroyi

6b Posterior margin of caudal fin with a narrow, clear whitish margin; margin of anal fin slightly angular; gill rakers 23-26 [Western Indian Ocean to western Pacific]

E. chlorostigma

\section{Comparative material examined}

Epinephelus areolatus: ANSP 54826, ZMUA-epare01, ZMUA-epare02, and ZMUAepare03.

Epinephelus chlorostigma: FLMNH_I 2006-0681, FLMNH_I 2007-1089, ANSP 162821, ANSP 163245, and ANSP 103722.

Epinephelus miliaris: FLMNH_I 2006-0784 and FLMNH_I 2006-0728.

Epinephelus polylepis: FLMNH_I 2005-1073.

Epinephelus geoffroyi: ZMUA-epgeo01 and ZMUA-epgeo02.

(See Suppl. material 1: Table S1 for more information.)

\section{Acknowledgments}

We would like to thank Dr Matthew T. Craig for providing us with helpful advice on our research. We would also like to thank Dr Xuan Zhuang for giving us her constructive comments. We would like to thank the Florida Museum of Natural History, University of Florida for providing us grouper specimens. We would also like to thank Benjamin W. Frable for checking the specimens from ANSP. We would like to thank Ji Feng, Third Institute of Oceanography, Ministry of Natural Resources, for the assistance with radiographs. We would also like to thank Lei Fan, Haoran Zhang, and Xiang Zhang for assistance in specimen collection. This work was supported by the National Key R \& D Program of China (2018YFD0900803) and the National Programme on Global Change and Air-Sea Interaction (GASI-02-SCS-YDsum).

\section{References}

Craig MT, Hastings PA (2007) A molecular phylogeny of the groupers of the subfamily Epinephelinae (Serranidae) with a revised classification of the Epinephelini. Ichthyological Research 54: 1-17. https://doi.org/10.1007/s10228-006-0367-x

Craig MT, Sadovy de Mitcheson YJ, Heemstra PC (2011) Groupers of the world: A Field and Market Guide. NISC (Pty) Ltd, Grahamstown, 356 pp.

Dalzell PJ, Adams TJH, Polunin NVC (1996) Coastal fisheries in the Pacific islands. Oceanography and Marine Biology: 395-531. http://www.spc.int/DigitalLibrary/Doc/FAME/ Reports/Dalzell_96_OMB.pdf

Darriba D, Taboada GL, Doallo R, Posada D (2012) jModelTest 2: more models, new heuristics and parallel computing. Nature methods 9: 1-772. https://doi.org/10.1038/nmeth.2109 
Frable BW, Tucker SJ, Walker HJ (2018) A new species of grouper, Epinephelus craigi (Perciformes: Epinephelidae), from the South China Sea. Ichthyological Research: 1-10. https:// doi.org/10.1007/s10228-018-0669-9

Gilles A, Miquelis A, Quignard JP, Faure É (2000) Molecular phylogeograpby of western Mediterranean dusky grouper Epinephelus marginatus. Comptes Rendus de l'Academie des Sciences - Serie III 323: 195-205. https://doi.org/10.1016/S0764-4469(00)00114-1

Guindon S, Gascuel O (2003) A simple, fast, and accurate algorithm to estimate large phylogenies by maximum likelihood. Systematic biology 52: 696-704. https://doi. org/10.1080/10635150390235520

Han J, Lv F, Cai H (2011) Detection of species-specific long VNTRs in mitochondrial control region and their application to identifying sympatric Hong Kong grouper (Epinephelus akaara) and yellow grouper (Epinephelus awoara). Molecular Ecology Resources 11: 215218. https://doi.org/10.1111/j.1755-0998.2010.02911.x

Heemstra PC, Randall JE (1993) FAO Species Catalog (Vol. 16). Groupers of the World (Family Serranidae, Subfamily Epinephelinae) An Annotated and Illustrated Catalogue of the Grouper, Rockcod, Hind, Coral Grouper and Lyretail Species Known to Date. FAO Fisheries Synopsis No. 125. FAO, Rome, 382 pp.

Kimura M (1980) A simple method for estimating evolutionary rates of base substitutions through comparative studies of nucleotide sequences. Journal of Molecular Evolution 16: 111-120. https://doi.org/10.1007/BF01731581

Kumar S, Stecher G, Tamura K (2016) MEGA7: molecular evolutionary genetics analysis version 7.0 for bigger datasets. Molecular biology and evolution 33: 1870-1874. https://doi. org/10.1093/molbev/msw054

Ma KY, Craig MT (2018) An Inconvenient Monophyly: An Update on the Taxonomy of the Groupers (Epinephelidae). Copeia 106: 443-456. https://doi.org/10.1643/CI-18-055

Ma KY, Craig MT, Choat JH, van Herwerden L (2016) The historical biogeography of groupers: Clade diversification patterns and processes. Molecular Phylogenetics and Evolution 100: 21-30. https://doi.org/10.1016/j.ympev.2016.02.012

Qu M, Tang W, Liu Q, Wang D, Ding S (2018) Genetic diversity within grouper species and a method for c hybrid identification using DNA barcoding and RYR3 marker. Molecular Phylogenetics and Evolution 121: 46-51. https://doi.org/10.1016/j.ympev.2017.12.031

Randall JE, Heemstra PC (1991) Revision of Indo-Pacific groupers (Perciformes: Serranidae: Epinephelinae), with descriptions of five new species. Indo-Pacific Fishes 20: 1-322.

Randall JE, Bogorodsky SV, Krupp F, Rose JM, Fricke R (2013) Epinephelus geoffroyi (Klunzinger, 1870) (Pisces: Serranidae), a valid species of grouper endemic to the Red Sea and Gulf of Aden. Zootaxa 3641: 524-532. https://doi.org/10.11646/zootaxa.3641.5.2

Richardson J (1846) Report on the ichthyology of the seas of China and Japan. Report of the British Association for the Advancement of Science $15^{\text {th }}$ meeting (1845): 187-320. https:// doi.org/10.5962/bhl.title.59530

Ronquist F, Teslenko M, Van Der Mark P, Ayres DL, Darling A, Höhna S, Larget B, Liu L, Suchard MA, Huelsenbeck JP (2012) Mrbayes 3.2: Efficient bayesian phylogenetic inference and model choice across a large model space. Systematic Biology 61: 539-542. https://doi.org/10.1093/sysbio/sys029 
Sabaj MH (2016) Standard Symbolic Codes for Institutional Resource Collections in Herpetology and Ichthyology: an Online Reference. Version 6.5 (16 August 2016). http://www. asih.org/ resources/standard-symbolic-codes-institutionalresource-collections-herpetology-ichthyology

Schlitzer R (2002) Interactive analysis and visualization of geoscience data with Ocean Data View. Computers \& geosciences 28: 1211-1218. https://doi.org/10.1016/S00983004(02)00040-7

Smith WL, Craig MT (2007) Casting the Percomorph Net Widely: The Importance of Broad Taxonomic Sampling in the Search for the Placement of Serranid and Percid Fishes. Copeia 2007: 35-55. https://doi.org/10.1643/0045-8511(2007)7[35:CTPNWT]2.0.CO;2

Ward RD, Zemlak TS, Innes BH, Last PR, Hebert PDN (2005) DNA barcoding Australia's fish species. Philosophical Transactions of the Royal Society B: Biological Sciences 360: 1847-1857. https://doi.org/10.1098/rstb.2005.1716

Zhuang X, Qu M, Zhang X, Ding S (2013) A Comprehensive Description and Evolutionary Analysis of 22 Grouper (Perciformes, Epinephelidae) Mitochondrial Genomes with Emphasis on Two Novel Genome Organizations. PLoS ONE 8: 1-14. https://doi. org/10.1371/journal.pone.0073561

\section{Supplementary material I}

\section{Table S1. Samples information}

Authors: Haohao Wu, Meng Qu, Hungdu Lin, Wei Tang, Shaoxiong Ding

Data type: samples data

Copyright notice: This dataset is made available under the Open Database License (http://opendatacommons.org/licenses/odbl/1.0/). The Open Database License $(\mathrm{ODbL})$ is a license agreement intended to allow users to freely share, modify, and use this Dataset while maintaining this same freedom for others, provided that the original source and author(s) are credited.

Link: https://doi.org/10.3897/zookeys.933.46406.suppl1 